\title{
Antisense Targeting of Perlecan Blocks Tumor Growth and Angiogenesis In Vivo
}

\author{
Bela Sharma, ${ }^{*}$ Melissa Handler, ${ }^{*}$ Inge Eichstetter, ${ }^{*}$ John M. Whitelock, ${ }^{\ddagger}$ Matthew A. Nugent, ${ }^{\S}$ and Renato V. Iozzo* \\ *Department of Pathology, Anatomy, and Cell Biology, and the Kimmel Cancer Center, Jefferson Medical College, Thomas Jefferson \\ University, Philadelphia, Pennsylvania 19107; ${ }^{\ddagger}$ CRC for Cardiac Technology, CSIRO Molecular Science, Sydney, Australia; and \\ ${ }^{\S}$ Department of Biochemistry, Boston University School of Medicine, Boston, Massachusetts 02118
}

\begin{abstract}
Perlecan, a ubiquitous heparan sulfate proteoglycan, possesses angiogenic and growth-promoting attributes primarily by acting as a coreceptor for basic fibroblast growth factor (FGF-2). In this report we blocked perlecan expression by using either constitutive CMV-driven or doxycyclineinducible antisense constructs. Growth of colon carcinoma cells was markedly attenuated upon obliteration of perlecan gene expression and these effects correlated with reduced responsiveness to and affinity for mitogenic keratinocyte growth factor (FGF-7). Exogenous perlecan effectively reconstituted the activity of FGF-7 in the perlecan-deficient cells. Moreover, soluble FGF-7 specifically bound immobilized perlecan in a heparan sulfate-independent manner. In both tumor xenografts induced by human colon carcinoma cells and tumor allografts induced by highly invasive mouse melanoma cells, perlecan suppression caused substantial inhibition of tumor growth and neovascularization. Thus, perlecan is a potent inducer of tumor growth and angiogenesis in vivo and therapeutic interventions targeting this key modulator of tumor progression may improve cancer treatment. (J. Clin. Invest. 1998. 102:1599-1608.) Key words: proteoglycans - heparan sulfate - fibroblast growth factor • FGF-2 - FGF-7
\end{abstract}

\section{Introduction}

The development of a well-vascularized tumor stroma is necessary to sustain the growth, invasion, and metastatic potential of most human and experimental tumors (1-3). Neoplastic cells activate intrinsic properties of resting vascular cells that turn on an angiogenic switch, a biological phenomenon that occurs early in malignancy, often during predevelopmental stages of tumor progression (4). Proteoglycans are major constituents of the tumor stroma and neovascular bed formation and play key regulatory functions during various stages of tumor development by influencing the structure of cell surface basement membranes and extracellular matrices (5). Among

B. Sharma and M. Handler contributed equally to this study.

Address correspondence to Renato V. Iozzo, Department of Pathology, Anatomy, and Cell Biology, Room 249 Jefferson Alumni Hall, Thomas Jefferson University, 1020 Locust St., Philadelphia, PA 19107. Phone: 215-503-2208; FAX: 215-923-7969; E-mail: iozzo@lac. jci.tju.edu

Received for publication 21 April 1998 and accepted in revised form 26 August 1998.

J. Clin. Invest.

(C) The American Society for Clinical Investigation, Inc. 0021-9738/98/10/1599/10 \$2.00

Volume 102, Number 8, October 1998, 1599-1608

http://www.jci.org the various angiogenic factors so far identified, the heparan sulfate proteoglycan perlecan (6), a modular proteoglycan with widespread tissue distribution (7), stands out as an important player. During mammalian development perlecan expression appears early in tissues of vasculogenesis. It is deposited along all the endothelial-lined vascular beds, both fenestrated and nonfenestrated, and this process correlates with the onset of tissue differentiation (8). Increased perlecan levels are detected in breast carcinomas (7) and in metastatic melanomas (9) and this correlates with a more aggressive phenotype (10). In tumor xenografts induced by human prostate carcinoma cells, human perlecan is deposited along the basement membrane of newly formed tumor vessels of obvious murine origin (7). Thus, perlecan may act as a scaffold for tumor angiogenesis.

Perlecan binds to basic fibroblast growth factor (FGF-2) ${ }^{1}$ (11) and acts as a low-affinity/high-capacity receptor, thereby promoting tumor angiogenesis (12). The biological activity of FGF-2, and perhaps other members of the FGF family, is significantly enhanced by heparin that can substitute for heparan sulfate. Cells that naturally lack heparan sulfate but overexpress high-affinity receptors for FGFs fail to show a significant mitogenic response to FGF-2 unless heparin is supplemented $(13,14)$. FGF-2 binds to the $\mathrm{NH}_{2}$-terminal heparan sulfate chains (15) and its release by proteolytic enzymes is a mechanism by which tumor cells ensure the generation of bioactive molecules at sites of invasion. Inhibition of endogenous perlecan levels suppresses autocrine and paracrine functions of FGF-2 in human melanoma cells (16) and blocks melanoma cell proliferation and invasion (17). However, in fibrosarcoma cells suppression of perlecan leads to an FGF-2-independent stimulation of their growth (18). Therefore, the cellular context appears to mediate the biological activity of perlecan during tumor progression.

The main goal of this study was to assess the role of perlecan in two well-studied cellular systems, i.e., human colon carcinoma and mouse melanoma cells. We generated stably transfected clones of both cell lines that express high levels of antisense perlecan cDNA. In both instances, tumor growth was markedly delayed in vitro and in the animal. Moreover, we show for the first time that perlecan acts as a coreceptor for FGF-7 in human colon carcinoma cells and that soluble FGF-7 specifically binds immobilized perlecan proteoglycan. Our findings indicate that perlecan expression is essential for an efficient blood supply since the growth suppression of antisenseexpressing tumor xenografts and allografts correlated with a marked decline of tumor neovascularization.

\section{Methods}

Materials. Media were purchased from Mediatech, Inc. (Herndon, VA). Human recombinant FGF-2 was obtained from Promega (Mad-

1. Abbreviation used in this paper: FGF, fibroblast growth factor. 
ison, WI). Human recombinant FGF-7, serum-free defined media, heparin, and doxycycline were from Sigma Chemical Co. (St. Louis, MO). FBS was obtained from Hyclone Laboratories, Inc. (Logan, UT). HCT116 cells were obtained from American Type Culture Collection (Rockville, MD). M2 melanoma cells were obtained from Dr. I.J. Fidler (M.D. Anderson Cancer Center, Houston, TX).

Antisense vector and generation of stably transfected clones. A human antisense construct comprising $\sim 1 \mathrm{~kb}$ (bp 3120-4120) of the human cDNA domain III (19) was cloned in the eukaryotic expression vector pcDNA3 (Invitrogen Corp., Carlsbad, CA). Proper orienta- tion of the insert was confirmed by DNA sequencing. Approximately $10^{8}$ HCT116 human colon carcinoma cells were transfected with 75 $\mu \mathrm{g}$ of antisense plasmid DNA and grown for $48 \mathrm{~h}$ in nonselective medium which allowed for the expression of the transfected gene. The cells were cultured in G418 (400 $\mu \mathrm{g} / \mathrm{ml})$ and clones were isolated by ring cloning and expanded as previously described (20).

Generation of perlecan antisense inducible (pTet-on) mouse M2 melanoma clones. Approximately $10^{8} \mathrm{M} 2$ cells were transfected with $40 \mu \mathrm{g}$ of the pTet-on regulatory plasmid (Clontech, Palo Alto, CA). To select for induction, 56 independent clones were isolated and tran-

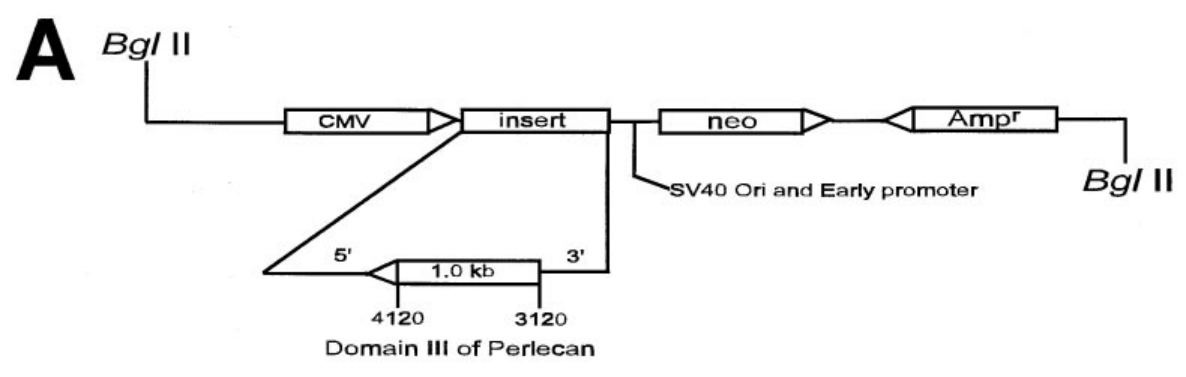

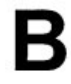

Perlecan AS IRNA
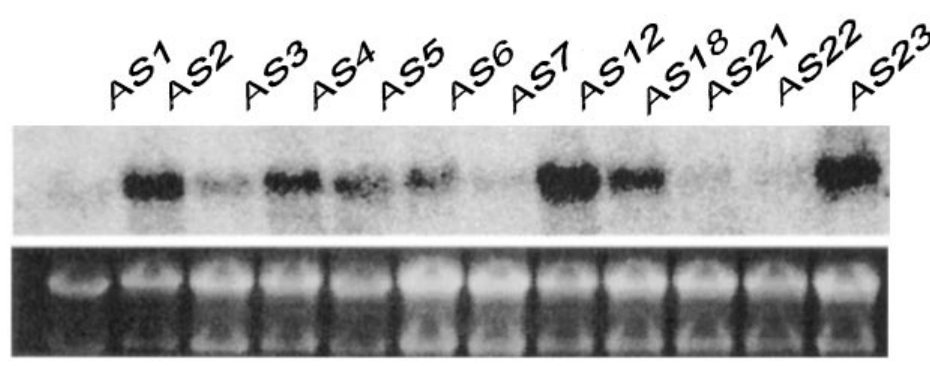

1

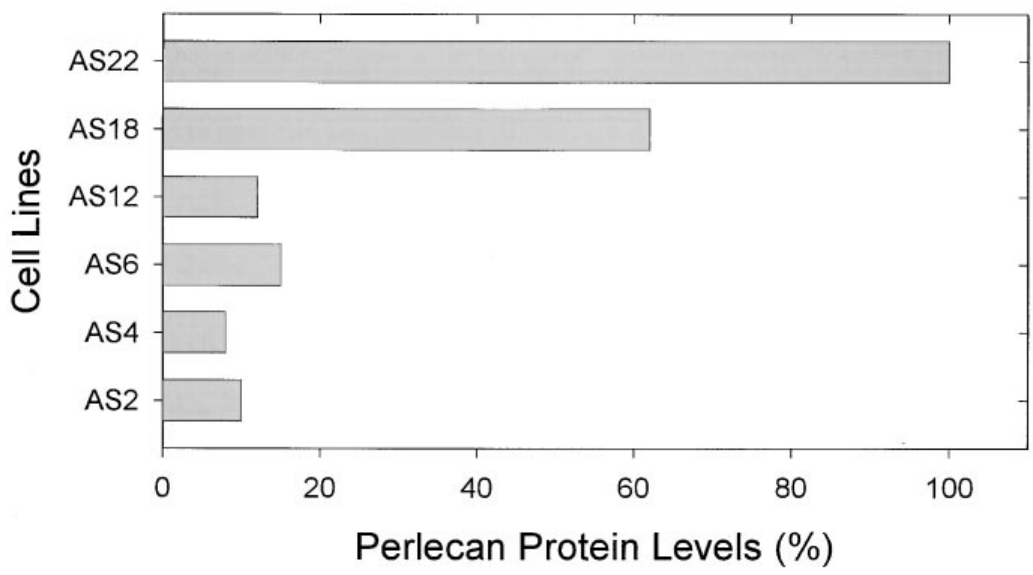

D
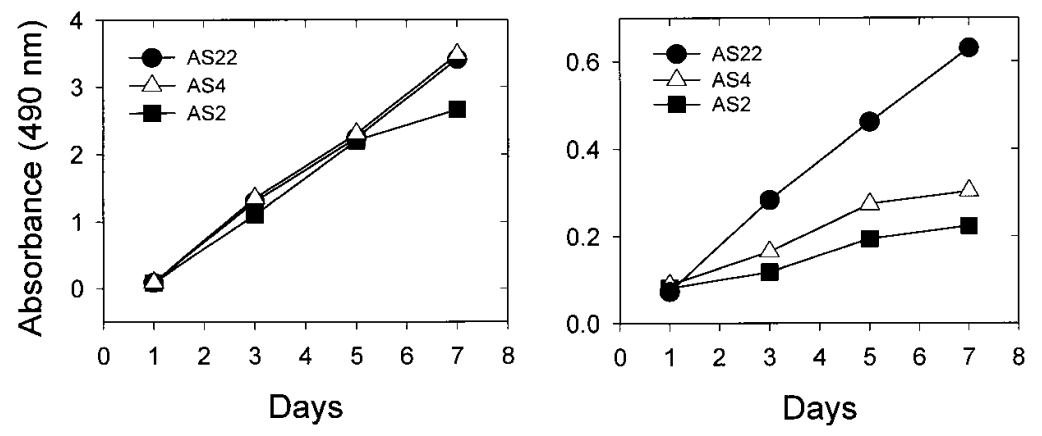

Figure 1. Suppression of perlecan by stable antisense transfection leads to reduced growth of human colon carcinoma cells. (A) Perlecan antisense construct. $(B)$ Northern blotting of the transfected clones showing the expected $1-\mathrm{kb}$ perlecan antisense $(A S)$ transcript. $(C)$ Western immunoblotting data showing expression of human perlecan as detected in serum-free medium conditioned by the designated clones for $48 \mathrm{~h}$ using a mouse monoclonal anti-human perlecan antibody (22) and chemiluminescence. $(D)$ Growth in the presence of $10 \%$ serum. $(E)$ Growth in serum-free medium. Each value is the mean of quadruplicate determinations with $\mathrm{SD}<$ $10 \%$ of the mean. $(F)$ Growth in soft agar of control and antisense expressing clones as indicated. Approximately $10^{5}$ cells were seeded in a sandwich of soft agar ( $0.3 \%$ top layer and $0.5 \%$ bottom layer) and cultured for $21 \mathrm{~d}$. Plates were fixed and photographed. The images were scanned with a Pixera scanning camera and colorized using Adobe Photoshop computer package. Scale bar, $200 \mu \mathrm{m}$. 
siently transfected with $10 \mu \mathrm{g}$ pTRE-pLUC plasmid. After various luciferase assays, performed according to the manufacturer's protocol (Promega), a highly responsive clone was isolated. An antisense construct was generated from a cDNA clone spanning domain III of murine perlecan (6) encompassing $\sim 1.9 \mathrm{~kb}$ of cDNA sequence (3396$5296 \mathrm{bp}$ ), and was ligated in the reverse orientation at the EcoRI site of the pTRE vector. Clones selected for highest luciferase activity were cotransfected with $40 \mu \mathrm{g}$ of the pTRE/perlecan antisense construct and $2 \mu \mathrm{g}$ of the hygromycin plasmid. After $48 \mathrm{~h}, 200 \mu \mathrm{g} / \mathrm{ml}$ hygromycin was added and the resistant clones were isolated and expanded as described above.

Northern and Western immunoblotting. RNA isolation and Northern blotting were as described before (18). For immunoblotting, HCT116 clones were grown to confluence in 6-well dishes containing DME and $10 \%$ FBS. After incubation for $18 \mathrm{~h}$ in serum-free DME, aliquots of the media were slot-blotted (21) and reacted with the monoclonal antibody 7B5, which recognizes domain III of human perlecan (22). M2 melanoma antisense-transfected clones were incubated for $48 \mathrm{~h}$ in serum-free DME with or without $2 \mu \mathrm{g} / \mathrm{ml}$ doxycycline. Several dilutions of the media were blotted and reacted with an affinity-purified rabbit polyclonal antibody which specifically recognizes mouse perlecan (8), followed by detection with chemiluminescence (21).

Responsiveness to growth factors. Cells were seeded in 48-well plates (Corning Glass Works, Corning, NY) in DME with or without $10 \%$ FBS. At each consecutive day, a colorimetric assay was performed (Cell Titer 96; Promega) where the amount of the reaction product is proportional to the number of viable cells. Routinely, after $1 \mathrm{~d}$, the medium was replaced with serum-free medium. After another day in culture, the cells were supplemented with $10 \mathrm{ng} / \mathrm{ml} \mathrm{FGF-2} \pm 10$ $\mu \mathrm{g} / \mathrm{ml}$ heparin and growth assays were performed. Similar protocols were used to assess FGF-7 activity.

Binding assays with ${ }^{125} \mathrm{I}-\mathrm{FGF}-7$ and ${ }^{125} \mathrm{I}-\mathrm{FGF}-2$, prepared by a modification of the Bolton-Hunter procedure, were conducted as previously described (23). Cells were plated at $10^{5}$ cells/well in 12-well culture plates in DME supplemented with $10 \%$ calf serum. After $2 \mathrm{~d}$, the cells were washed with ice-cold binding buffer (DME, $15 \mathrm{mM}$ Hepes, $\mathrm{pH} 7.4,0.05 \%$ gelatin) and incubated at $4^{\circ} \mathrm{C}$ for $10 \mathrm{~min} .{ }^{125} \mathrm{I}-$ FGF-7 or ${ }^{125}$ I-FGF-2 was added at the indicated concentrations and cells were incubated at $4^{\circ} \mathrm{C}$ for $2.5 \mathrm{~h}$. At the end of the binding period, cells were washed three times with ice-cold binding buffer. Proteoglycan-bound ${ }^{125} \mathrm{I}-\mathrm{FGF}$ was removed with a rapid wash $(\sim 10 \mathrm{~s})$ using $20 \mathrm{mM}$ Hepes, $1 \mathrm{M} \mathrm{NaCl}, \mathrm{pH}$ 7.0. Cell surface receptor-bound ${ }^{125}$ I-FGF was subsequently extracted with two washes in $10 \mathrm{mM} \mathrm{Na}$ acetate, $1 \mathrm{M} \mathrm{NaCl}$, pH 5.0. Nonspecific binding was determined empirically at four concentrations of ${ }^{125} \mathrm{I}-\mathrm{FGF}$ by competing with $1 \mu \mathrm{g} / \mathrm{ml}$ unlabeled FGF, and equations were derived to determine nonspecific binding at each ${ }^{125} \mathrm{I}$-FGF concentration used. Specific binding values were normalized for cell number and equilibrium dissociation constants and numbers of receptor sites per cell determined by Scatchard analysis (23).

Purification of perlecan and binding to FGF-7. Perlecan was purified to homogeneity from the medium conditioned by human umbilical artery endothelial cells by chromatography on DEAESepharose followed by immunoaffinity chromatography using A71 monoclonal antibody (15) coupled to Sepharose beads (manuscript in preparation). In brief, perlecan was eluted from the DEAE column with $1 \mathrm{M} \mathrm{NaCl}$ and applied directly to the immunoaffinity column eluted with $6 \mathrm{M}$ urea. The urea in the eluate was removed by diafiltration using Centricon 30 concentrating vessels. The purity of the final perlecan product was determined by gel electrophoresis and Western immunoblotting using polyclonal 906 antibodies that recognize both the murine and human protein core (a gift of Dr. M. Dziadek) as well as by monoclonal antiperlecan antibodies (15). The final product was essentially pure proteoglycan with an estimated molecular mass of $\sim 500 \mathrm{kD}$ carrying heparan sulfate side chains.

To detect specific interaction between perlecan and FGF-7, we immobilized scalar concentrations of perlecan or collagen type I (Vi-

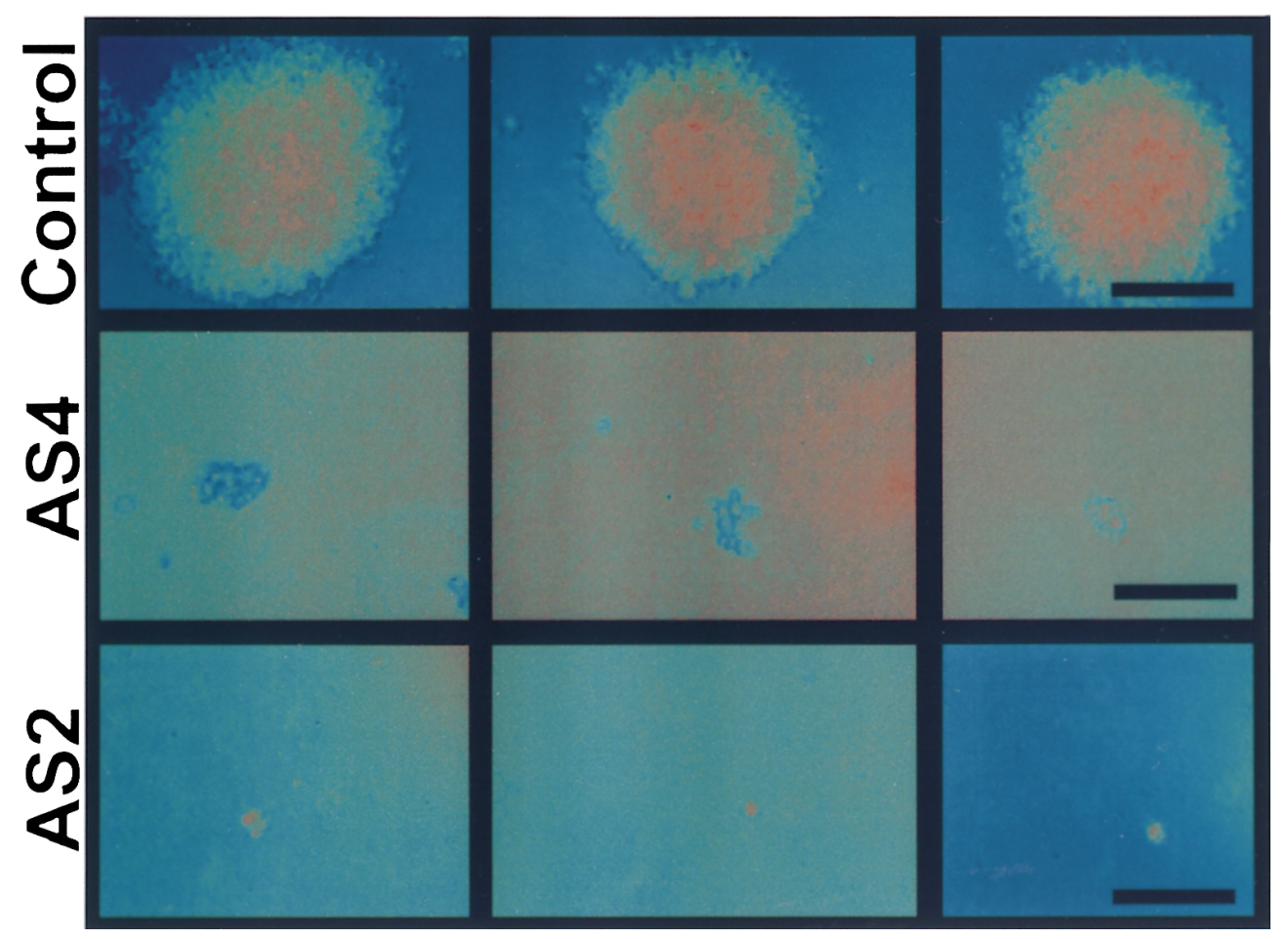

Figure 1 (Continued) 
trogen 100, Celtrix) onto nitrocellulose membranes by slot blotting. Membranes were washed twice with TBS (Tris-buffered saline, 25 $\mathrm{mM}$ Tris- $\mathrm{HCl}, 150 \mathrm{mM} \mathrm{NaCl}$ ) and blocked overnight at $4^{\circ} \mathrm{C}$ with $5 \%$ bovine calf serum, $5 \%$ nonfat milk, and TBS-T (TBS- $0.1 \%$ Tween 20). After three 5-min washes, the membranes were incubated with human recombinant FGF-7 $(100 \mathrm{ng} / \mathrm{ml}$ in $2.5 \%$ bovine calf serum, $2.5 \%$ nonfat milk, and TBS-T) at room temperature for $1 \mathrm{~h}$. After three 5-min washes, the membranes were incubated with an antiFGF-7 antibody (C-19; Santa Cruz Biotechnology, Santa Cruz, CA) at $5 \mu \mathrm{g} / \mathrm{ml}$. After three additional 5-min washes, the membranes were incubated for $1 \mathrm{~h}$ with secondary antibody $(1: 5,000)$, washed again, and developed using ECL detection system (Amersham, Arlington Heights, IL).

Growth in soft agar and in mice. In vitro tumorigenicity was tested by growth in soft agar (20). Animal experiments were performed according to both institutional and National Institutes of Health guidelines. To test for growth in vivo, 18 NCR nude mice (males, 5-6 wk old) were purchased from Taconic Farms Inc. (Germantown, NY) and kept in a barrier care facility. Antisense-expressing and nonexpressing clones were injected at a density of $\sim 1.5 \times 10^{6}$ cells. For each cell type, six animals received injections subcutaneously in the mid-dorsum. A highly responsive mouse M2 melanoma clone was tested in syngeneic $\mathrm{C} 3 \mathrm{H} / \mathrm{HeN}$ mice (males, 5-6 wk old) purchased from Harlan Sprague Dawley Inc. (Indianapolis, IN). The cells $(\sim 1.1 \times$ $10^{6}$ ) were injected in the subcutaneous region of the mid-dorsum of 20 animals. The drinking water was supplemented with either 5\% sucrose or $5 \%$ sucrose/doxycycline $(400 \mu \mathrm{g} / \mathrm{ml})$. Volumes were measured with a microcaliper according to the formula: $(4 / 3 \pi)(a / 2)^{2}(b / 2)$; where $a$ and $b$ represent the width and length of the tumors, respectively. Animals were killed by cervical dislocation and subjected to careful necropsy. Portions of the tumors were immediately frozen in liquid nitrogen for nucleic acid and immunochemical analyses, whereas the remaining were fixed in $10 \%$ formaldehyde and processed for histology and immunohistochemistry.

\section{Results}

Abrogated perlecan gene expression causes growth suppression in human colon carcinoma cells. To investigate the role of perlecan in the growth of colon carcinoma cells, we generated stable transfected clones expressing an antisense cDNA targeting domain III of perlecan (Fig. $1 A$ ). Several clones expressed the antisense transcript (Fig. $1 B$ ) and the protein core levels correlated well with the antisense mRNA levels (Fig. $1 C$ ). Two antisense-expressing (AS4 and AS2) clones exhibiting 85-90\% suppression of perlecan synthesis and a nonexpressing (AS22) clone were studied in detail. In several growth experiments containing $10 \%$ serum (Fig. $1 \mathrm{D}$ ) no significant difference in growth was observed in either the wild-type or transfected cells. However, in the absence of serum (not shown) or in serum-free defined medium containing transferrin, selenium, and insulin, there was a significant decrease in the growth of the antisense-expressing cell lines (Fig. $1 \mathrm{E}$ ). Because perlecan is present in bovine serum (our unpublished
A

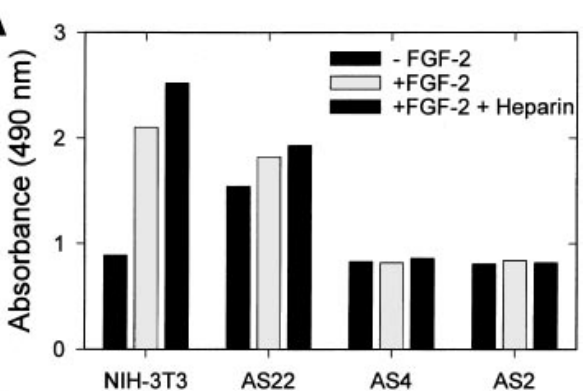

B
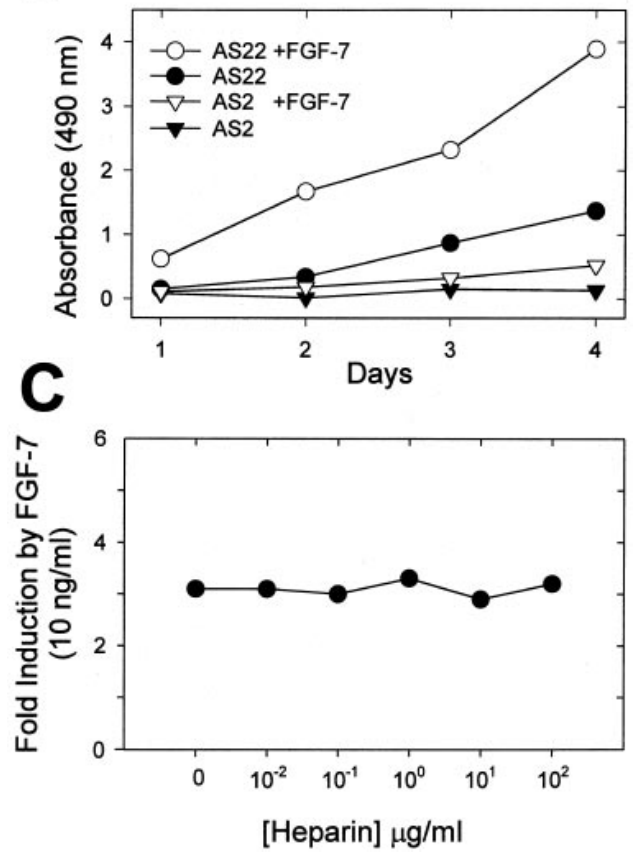

D

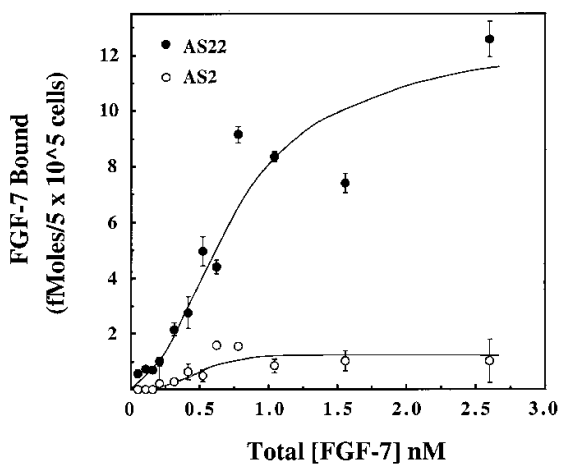

E

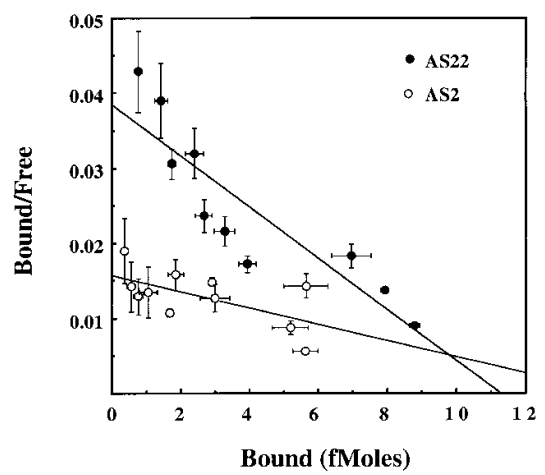

Figure 2. Suppression of perlecan affects responsiveness to FGF-7 but not FGF-2. ( $A$ ) Growth of NIH3T3 fibroblasts and antisense-expressing and nonexpressing tumor clones after a 2-d exposure to $10 \mathrm{ng} / \mathrm{ml} \mathrm{FGF-2}$ with or without $10 \mu \mathrm{g} / \mathrm{ml}$ heparin as indicated. The values represent the means of quintuplicate samples with SD $<10 \%$ of the mean. (B) Growth of control (AS22) and antisense-expressing (AS2) cells in serum-free defined media supplemented with or without $10 \mathrm{ng} / \mathrm{ml} \mathrm{FGF-7} \mathrm{as} \mathrm{indi-}$ cated. The values represent the means of quintuplicate samples with $\mathrm{SD}<10 \%$ of the mean. $(C)$ Growth induction of AS22 cells caused by FGF-7 $(10 \mathrm{ng} / \mathrm{ml})$ and increasing concentrations of heparin as indicated. The values are the means of quadruplicate samples with $\mathrm{SD}<5 \%$ of the mean. (D) Specific FGF-7 binding to heparan sulfate proteoglycan sites on AS2 (open circles) and AS22 (filled circles) cells was determined as described in Methods. Cells were incubated with the indicated concentration of ${ }^{125}$ I-FGF-7 (Total [FGF-7]) in triplicate and the means \pm SEM bound are presented. $(E)$ FGF-7 receptor binding data for AS2 (open circles) and AS22 (filled circles) cells were analyzed by the method of Scatchard. $(F)$ FGF-2 binding to heparan sulfate proteoglycan sites on AS2 (open circles) and AS22 (filled circles) cells was determined as described in Methods. Cells were incubated with the indicated concentration of ${ }^{125}$ I-FGF-2 (Total $[F G F-2]$ ) in triplicate and the means \pm SEM bound are presented. $(G)$ FGF-2 receptor binding data for AS2 (open circles) and AS22 (filled circles) cells were analyzed by the method of Scatchard. 
observation) we interpret these data to indicate that the presence of perlecan in the serum is responsible, at least in part, for the lack of growth inhibition in the antisense-expressing clones. The differential growth observed in vitro was confirmed by growth studies in soft agar (Fig. $1 F$ ). The antisense-expressing clones (AS4 and AS2) generated very small colonies (AS4, $10.6 \mu \mathrm{m} \pm 3.4, n=42$; AS2, $6.9 \mu \mathrm{m} \pm 2.6, n=46)$ whereas the control, AS22, produced much larger colonies $(575 \mu \mathrm{m} \pm 17$, $n=40)$. Therefore, a reduction in perlecan gene expression leads to growth suppression in the colon carcinoma cells.

Growth suppression in the antisense-expressing cells correlates with a reduced responsiveness to recombinant FGF-7 but not FGF-2. To investigate the growth changes further, we performed growth curves in serum-free defined medium with various combinations of recombinant human FGF-2 and FGF-7 with or without the cofactor heparin. As a positive control for FGF-2 activity, we tested NIH-3T3 fibroblasts known to be responsive to FGF-2 (24). As expected, the NIH-3T3 cells responded well to FGF-2 with a $>2.5$-fold increase in cell number (Fig. $2 \mathrm{~A}$ ). The presence of heparin led to a slight increase in cell growth. In contrast, both perlecan antisense clones along with the control cell line showed no appreciable response to the FGF-2 (Fig. $2 A$ ). Thus, FGF-2 is not involved in modulating the growth of these epithelial-derived tumor cells.

Next, we determined the effects of FGF-7, a member of the FGF family that acts primarily on epithelial cells (25). The control AS22 cell line responded quite well to FGF-7 (Fig. 2 $B)$, with a greater than fourfold increase in cell number after a 4-d exposure to $10 \mathrm{ng} / \mathrm{ml}$ FGF-7. In contrast, the antisenseexpressing clones AS2 (Fig. 2 B) and AS4 (not shown) did not significantly respond to FGF-7. These experiments were re-
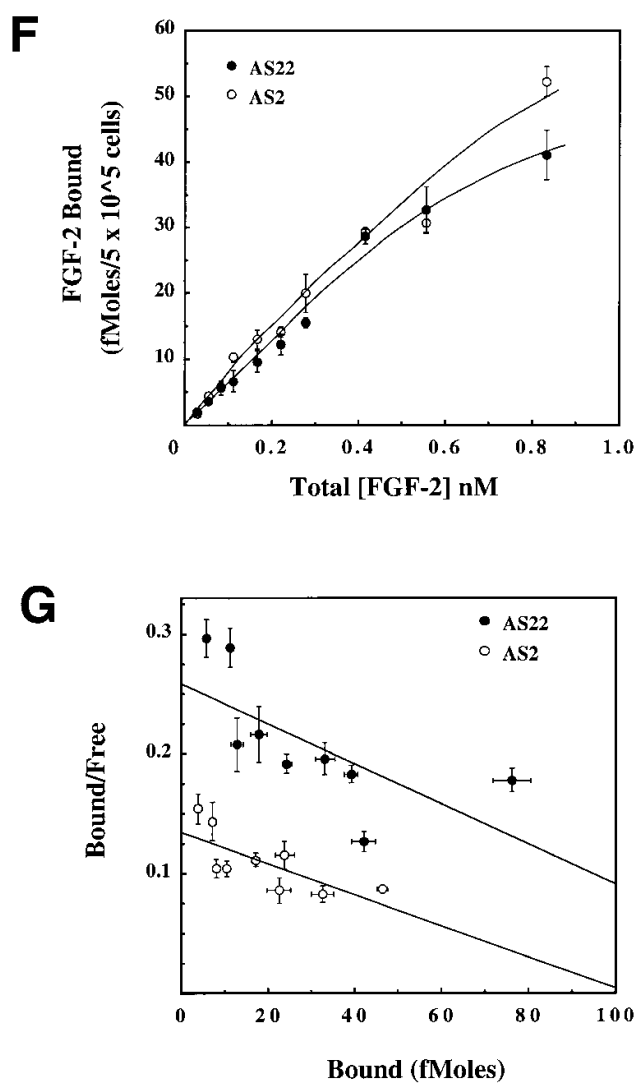

Figure 2 (Continued) peated several times and in all cases a lack of responsiveness to recombinant FGF-7 was evident only in the perlecan-deficient cells. Moreover, increasing concentrations of heparin (from 0.01 to $100 \mu \mathrm{g} / \mathrm{ml}$ ) did not affect the action of FGF-7 on AS22 cells (Fig. 2 C), suggesting that the perlecan protein core may be directly involved in modulating FGF-7 activity.

To investigate further this differential response, we iodinated both FGF-7 and FGF-2 and performed several binding experiments (23). AS2 cells bound significantly less FGF-7 than did AS22 cells (Fig. 2 D). In particular, the amount of FGF-7 that bound to heparan sulfate proteoglycan sites on AS2 cells was reduced by $\sim 90 \%$ vis à vis the control AS22 cells. FGF-7 receptor binding was also reduced in AS2 cells compared with AS22 cells as a result of a threefold reduction in binding affinity (Fig. $2 \mathrm{E}$ ). Single site linear regression analysis (23) on the binding data gave $K_{\mathrm{d}}=1.85 \pm 0.78 \mathrm{nM}$ for AS2 and $K_{\mathrm{d}}=0.58 \pm 0.11 \mathrm{nM}$ for AS22. The number of FGF-7 receptor sites was similar in the two cell lines $(17,500 \pm 1,700$

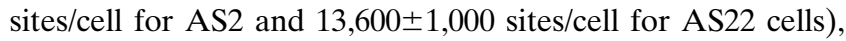
suggesting that the AS2 cells do not simply represent a receptor-deficient clone. In contrast, total FGF-2 binding was not significantly different on AS2 compared with AS-22 cells (Fig. $2, F$ and $G)$. The amount of FGF-2 bound to proteoglycan sites on the two cell lines was not different (Fig. $2 F$ ). FGF-2 receptor binding affinity was unchanged; however, a slightly reduced $(\sim 30 \%)$ number of receptor sites was present on the AS2 compared with the AS22 cells (Fig. $2 G$ ). Single site linear regression analysis was performed on the FGF-2 receptor binding data (Fig. $2 G$ ) with $K_{\mathrm{d}}=1.5 \pm 0.5 \mathrm{nM}$ for AS2 and $K_{\mathrm{d}}=$ $1.2 \pm 0.5 \mathrm{nM}$ for AS22, and 12,000 $\pm 1,000$ sites/cell for AS2 and $18,000 \pm 2,000$ sites/cell for AS22 cells.

Collectively, these results establish for the first time a direct interaction between perlecan and FGF-7 and indicate that suppression of perlecan gene expression results in a heparin-independent suppression of FGF-7 binding and receptor activation.

Purified human perlecan reconstitutes full FGF-7 activity on the perlecan-deficient cells and specifically binds soluble FGF-7. To directly test the effects of perlecan on FGF-7 activity, we immunopurified $\sim 0.5 \mathrm{mg}$ of human perlecan from media conditioned by umbilical artery endothelial cells, using A71 monoclonal antiperlecan antibodies (15) coupled to Sepharose beads. The purity of the final perlecan preparation was assessed by gel electrophoresis and Western immunoblotting using both polyclonal and monoclonal antibodies directed against the protein core (Fig. $3 A$ ). In both cases, only high molecular mass proteoglycan was detected that barely penetrated the $4-15 \%$ gradient gel. No degradation products, which would have been detected by the polyclonal antiserum, were noted. When tested in serum-free medium growth assays, exogenous perlecan reconstituted completely the mitogenic activity of FGF-7 in the AS2 perlecan-deficient cells with about threefold induction of growth (Fig. $3 B$ ), comparable to the mitogenic effects induced by FGF-7 alone in the control cells (see Fig. 2, $B$ and $C$ ). In contrast, FGF-7 or bovine serum albumin were totally ineffective, whereas perlecan alone caused an $\sim 30 \%$ induction of growth. These data corroborate the results obtained in the growth experiments shown above and further suggest an autocrine function for perlecan. The concentrations of perlecan we used were relatively low, i.e., 5 and $25 \mu \mathrm{g} / \mathrm{ml}$ which correspond to $\sim 10$ and $50 \mathrm{nM}$, respectively (based on an average molecular mass of $\sim 500 \mathrm{kD}$ for the fully glycosylated perlecan). Moreover, perlecan immobilized on nitrocel- 
lulose membranes was capable of specifically binding $\left(r^{2}=\right.$ 0.978) soluble FGF-7 as detected by Western immunoblotting (Fig. $3 \mathrm{C}$ ). In contrast, collagen type I did not bind at all. In separate experiments, coincubation with increasing concentrations $(0.1-10 \mu \mathrm{M})$ of heparan sulfate from porcine mucosa (average molecular mass $\sim 7.5 \mathrm{kD}$ ) did not cause any appreciable inhibition of FGF-7 binding to immobilized perlecan (Fig. 3 $D)$. Of note, the highest concentration of heparan sulfate used $(10 \mu \mathrm{M}=75 \mu \mathrm{g})$ was estimated to be $>440$ molar excess vis à vis the heparan sulfate present in the immobilized perlecan (4 $\mu \mathrm{g}$ of perlecan with an estimated molecular mass of $\sim 525 \mathrm{kD}$ contains an average of three heparan sulfate chains of $\sim 20 \mathrm{kD}$ each; thus $\sim 450 \mathrm{ng}$ of heparan sulfate, equivalent to $\sim 22.8$ $\mathrm{nM}$, was present in each slot). Finally, digestion of perlecan with heparitinase did not appreciably change the binding to soluble FGF-7 (Fig. 3 E). Collectively, these results indicate that perlecan is an efficient and physiological cofactor for FGF-7 activity and suggest that the core protein is directly involved in mediating this interaction.

Reduced tumor growth and angiogenesis in the antisenseexpressing clones in vivo. To investigate the growth of antisense-expressing and nonexpressing colon carcinoma cells, $\sim 1.5 \times 10^{6}$ cells of the three clones were injected into nude mice (six animals/clone). Within $\sim 20 \mathrm{~d}$ after injection, AS22 formed tumors much larger than AS2; intermediate size tumors were observed in the AS4 cell line (Fig. $4 A$ ). These growth rates remained relatively constant, and at $38 \mathrm{~d}$ after injection the mean tumor volume of the control animals was $\sim 2$ and $\sim 15$ times that of the AS4 and AS2 clones, respectively. Thus, it appears that although highly efficient in vitro, AS4 cells are less efficient in reducing perlecan-mediated angiogenesis in vivo. The in vivo growth rates correlated with the perlecan protein core levels in tumor extracts (Fig. $4 \mathrm{~B}$ ) as determined by Western immunoblotting using a monoclonal antibody directed toward domain III of human perlecan (22). These data indicate that reduction of perlecan levels contributes to delayed tumor growth in vivo.

When the tumor xenografts were analyzed by light microscopy it was evident that the subcutaneous neoplasms generated by the nonexpressing AS22 clone contained a large number of blood vessels at the tumor edges (Fig. $4 \mathrm{C}$ ) and exhibited an aggressive phenotype, often infiltrating through the deep fascia and skeletal muscle (Fig. $4 D$ ). In contrast, the tumor xenografts generated by the perlecan antisense-express-
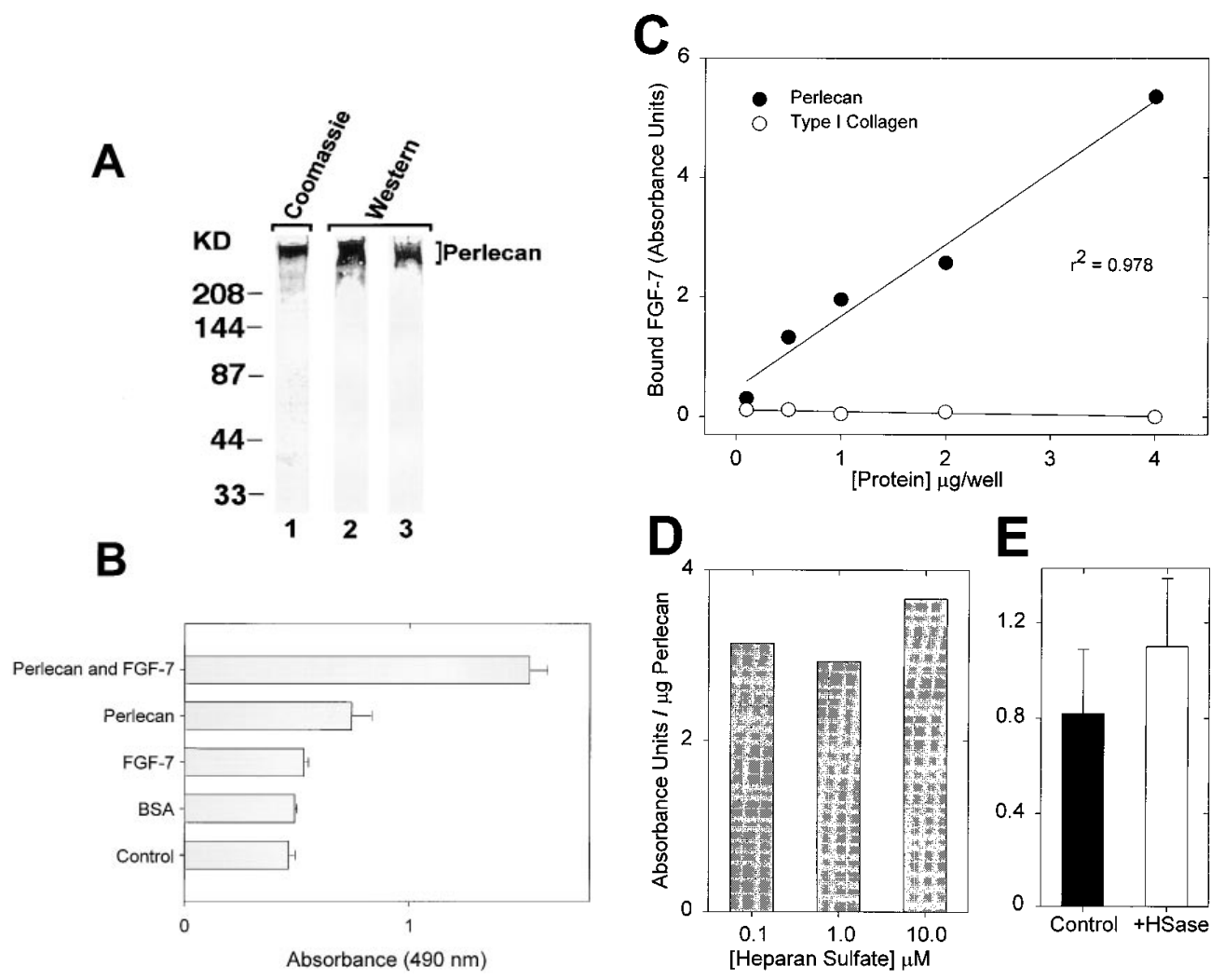

Figure 3. Perlecan reconstitutes the growth-promoting activity of FGF-7 in perlecan-deficient cells and binds to FGF-7. (A) Purity of the human perlecan immunopurified from media conditioned by umbilical artery endothelial cells. About $5 \mu \mathrm{g}$ of immunopurified perlecan was electrophoresed through a 4-15\% SDS-PAGE gel and stained with Coomassie blue R-250 (lane 1), or immunoblotted and probed with either a polyclonal rabbit antibody that recognizes both murine and human perlecan pro-

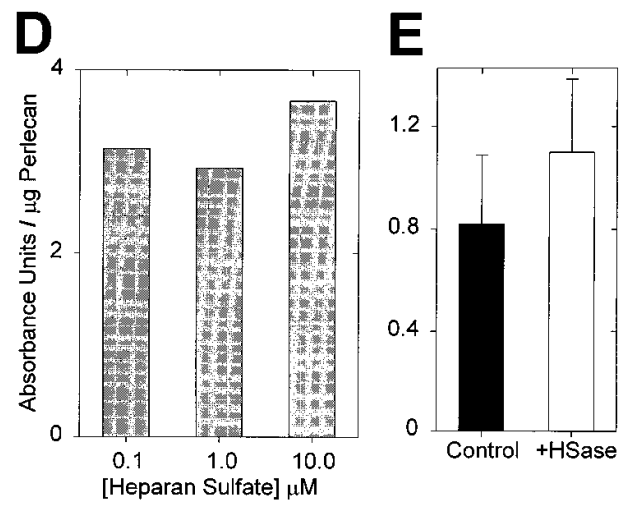
tein core (lane 2) or monoclonal antibody A71 that reacts with domain I of human perlecan (15) (lane 3). The migration of size markers is indicated in the left margin in kilodaltons. (B) After $2 \mathrm{~d}$ in serum-free media, the AS22 (control) and AS2 (antisenseexpressing) cells were supplemented with or without $10 \mathrm{ng} / \mathrm{ml}$ FGF-7 and $25 \mu \mathrm{g} / \mathrm{ml}$ perlecan. Cell proliferation assay was performed after two additional days in culture. The values are the means of quadruplicate determinations \pm SD. An independent experiment gave comparable results. $(C)$ Binding of soluble FGF-7 to immobilized perlecan or type I collagen as detected by protein overlay assay and immunoblotting. The plot shows the binding of soluble FGF-7 (100 ng/ml) to either perlecan or type I collagen at the designated concentrations immobilized on a nitrocellulose membrane. The blots were washed and the bound FGF-7 was detected with anti-human FGF-7 antibody and visualized by chemiluminescence. The values were normalized against background and represent the mean from three independent experiments. The $r$ value was calculated using nonlinear polynomial regression. $(D)$ Binding of soluble FGF-7 to immobilized perlecan $(4 \mu \mathrm{g})$ in the presence of increasing concentrations of heparan sulfate as indicated. The values are the mean of duplicate determinations. (E) Binding of soluble FGF-7 to immobilized perlecan before and after heparitinase (HSase) treatment. Various concentrations $(1-8 \mu \mathrm{g})$ of perlecan were incubated for $2 \mathrm{~h}$ at $37^{\circ} \mathrm{C}$ with $50 \mathrm{mU} / \mathrm{ml}$ heparitinase I (EC 4.2.2.8; Sigma) in $50 \mathrm{mM}$ Tris-HCl, containing $20 \mathrm{mM} \mathrm{Ca}$ acetate, $10 \mu \mathrm{g}$ heparan sulfate as carrier, $1 \mathrm{mM}$ phenylmethylsulfonyl fluoride, and $10 \mu \mathrm{g}$ each leupeptin and pepstatin (41). The reactions were stopped with 100 mM EDTA, slot-blotted into nitrocellulose, and incubated with FGF-7 and anti-FGF-7 antibodies as in $C$. The values are the means of quadruplicate determinations \pm SEM. 
ing clones showed well-demarcated borders with significantly less neovascularization (Fig. $4 \mathrm{E}$ ) and lack of infiltration of the skeletal muscle (Fig. 4 F).

To investigate further the neovascularization of the tumor xenografts, we immunostained the tumor tissues with a rabbit anti-mouse perlecan antibody (8). The results showed a marked reduction in the staining of the endothelial blood vessels in the antisense-expressing tumors, with a significant decrease in both intratumoral and peritumoral angiogenesis (Fig. $5 \mathrm{~A}$ ). (Operationally, we use the latter term to include recognizable microvessels within $200 \mu \mathrm{m}$ from the tumor border.) Comparable results (not shown) were obtained with an antibody against PECAM-1 (CD31) which has been used before to mark endothelial cells in tumor xenografts (26). To assess quantitatively the tumor vessel density, we counted all the immunoreactive microvessels at a magnification of 200 (i.e., 0.74 $\mathrm{mm}^{2}$ /field) according to previous protocols (27). The capillary density was statistically reduced $(P<0.0001)$ in the antisense AS2 clones (Fig. $5 \mathrm{~B}$ ). Of note, the peritumoral capillary density was suppressed more than the intratumoral capillary density, 16 vs. $33 \%$ of control values, respectively (Fig. 5 B). Collectively, these results indicate that synthesis of perlecan by human colon carcinoma cells has a beneficial effect on tumor growth in vivo and that lack of perlecan leads to an attenuated vascular supply. Our results further suggest that intratumoral and peritumoral blood vessels are differentially affected by perlecan released by the growing carcinoma cells.

Conditional abrogation of perlecan in highly invasive mouse melanoma cells suppresses tumor growth in syngeneic animals. To investigate further the role of mammalian perlecan in tu- morigenesis, we used mouse M2 cells, a highly invasive murine melanoma cell line (28). We chose this cellular system for several reasons. First, M2 melanoma cells synthesize high levels of perlecan (6). Second, these cells grow very well in syngeneic $\mathrm{C} 3 \mathrm{H} / \mathrm{HeN}$ hosts and have been used for assessing invasion and metastases (28). Third, melanoma cells respond to FGF-2 (24) and their growth is inhibited by antisense strategies targeting FGF-2 (29) or its receptor (26). We used an inducible system that allows selection of clones highly responsive to exogenous doxycycline, a derivative of tetracycline (30). We selected a region in domain III of mouse perlecan comparable to that used in the human colon carcinoma cells. Several clones showed variable responses to doxycycline, ranging from no effect to marked $(\sim 82 \%)$ suppression of perlecan gene expression (Fig. $6 A$ ). The most responsive clone (T25-33) showed a lack of response to FGF-2 under doxycycline treatment (Fig. $6 B$ ). To test for tumorigenicity in vivo, these cells were injected subcutaneously in the mid-dorsi of a cohort $(n=20)$ of syngeneic $\mathrm{C} 3 \mathrm{H} / \mathrm{HeN}$ male mice. Half of the mice received in their drinking water $5 \%$ sucrose alone as control, whereas the other half received $5 \%$ sucrose plus doxycycline $(400 \mu \mathrm{g} / \mathrm{ml})$ to induce the antisense perlecan expression. The results clearly showed a profound suppression of tumor allograft growth (Fig. $6 C$ ). The tumors of most control animals reached nearly $3 \mathrm{~cm}^{3}$ at $25 \mathrm{~d}$ after injection and these mice needed to be killed. In contrast, all the doxycycline-treated animals never reached a volume $>0.4 \mathrm{~cm}^{3}$. To obtain tissue for comparative histology we killed some of the antisense animals by day 28 , and allowed the others to live for a longer time. In a significant proportion of the antisense-expressing animals (4/10) no tumor was ob-
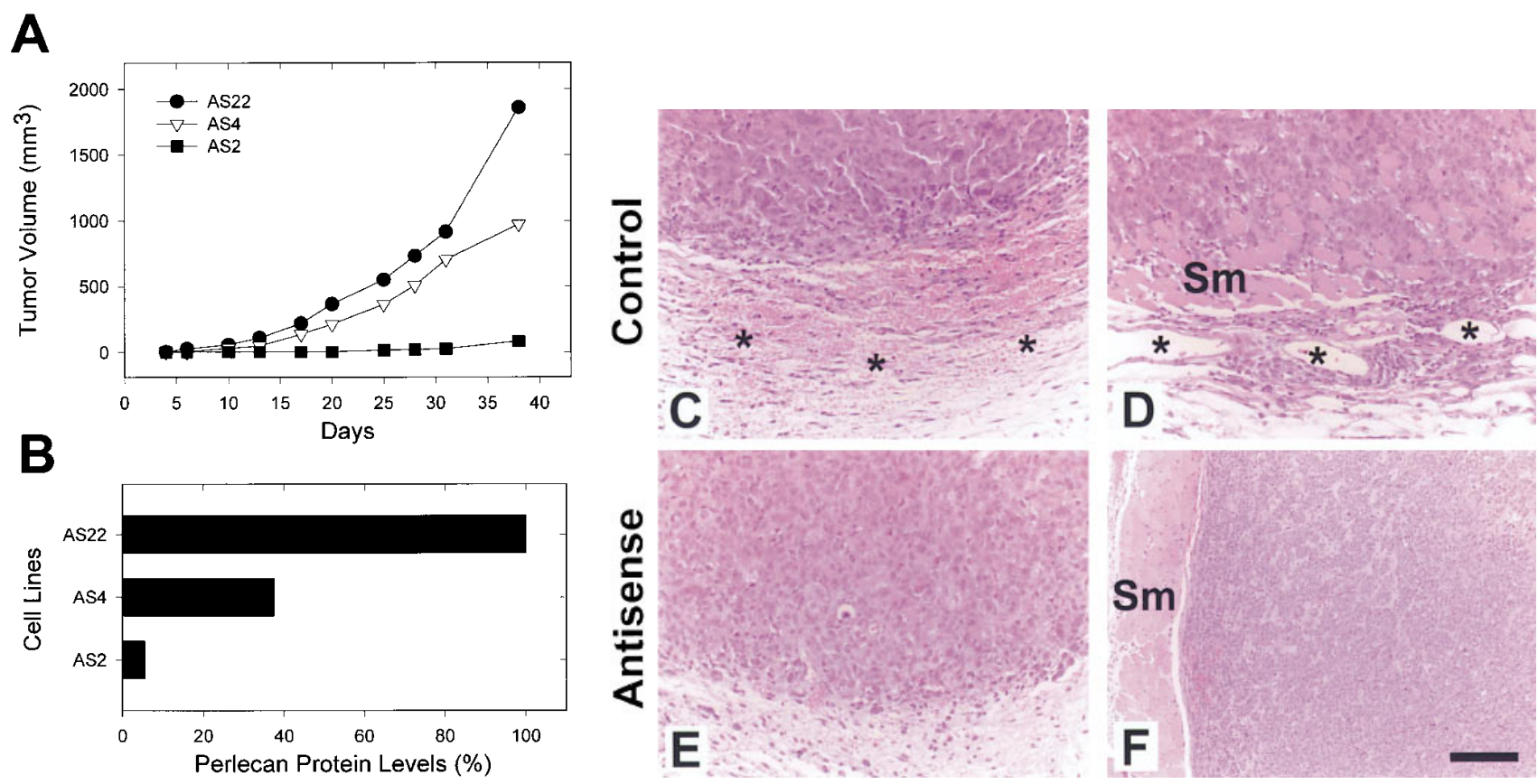

Figure 4. Halting perlecan gene expression leads to reduced tumor growth in nude mice. $(A)$ Kinetics of tumor growth induced by the subcutaneous injection of control (AS22) and two antisense-expressing clones (AS4 and AS2). Approximately $1.5 \times 10^{6}$ cells were individually injected into the mid-dorsum of NCR nude mice ( $n=6 /$ each cell line). The derived volumes represent the means with SD $<15 \%$ of the mean. $(B)$ Perlecan protein levels in tumor extracts as determined by Western immunoblotting using a monoclonal mouse anti-human perlecan antibody and chemiluminescence. Each value is the mean of two independent samples. ( $C$ and $D)$ Morphology of AS22 control. $(E$ and $F)$ Morphology of AS2 antisense-expressing tumors. Notice the presence of numerous microvessels in the peritumoral region (asterisks, $C$ and $D$ ) and the infiltration of the deep skeletal muscle $(\mathrm{Sm})$ by the control tumor cells $(D)$. In contrast, the reduction of perlecan expression leads to reduced tumor angiogenesis $(E)$ and inefficient muscular invasion $(F)$. Scale bar, $50 \mu \mathrm{m}$. 


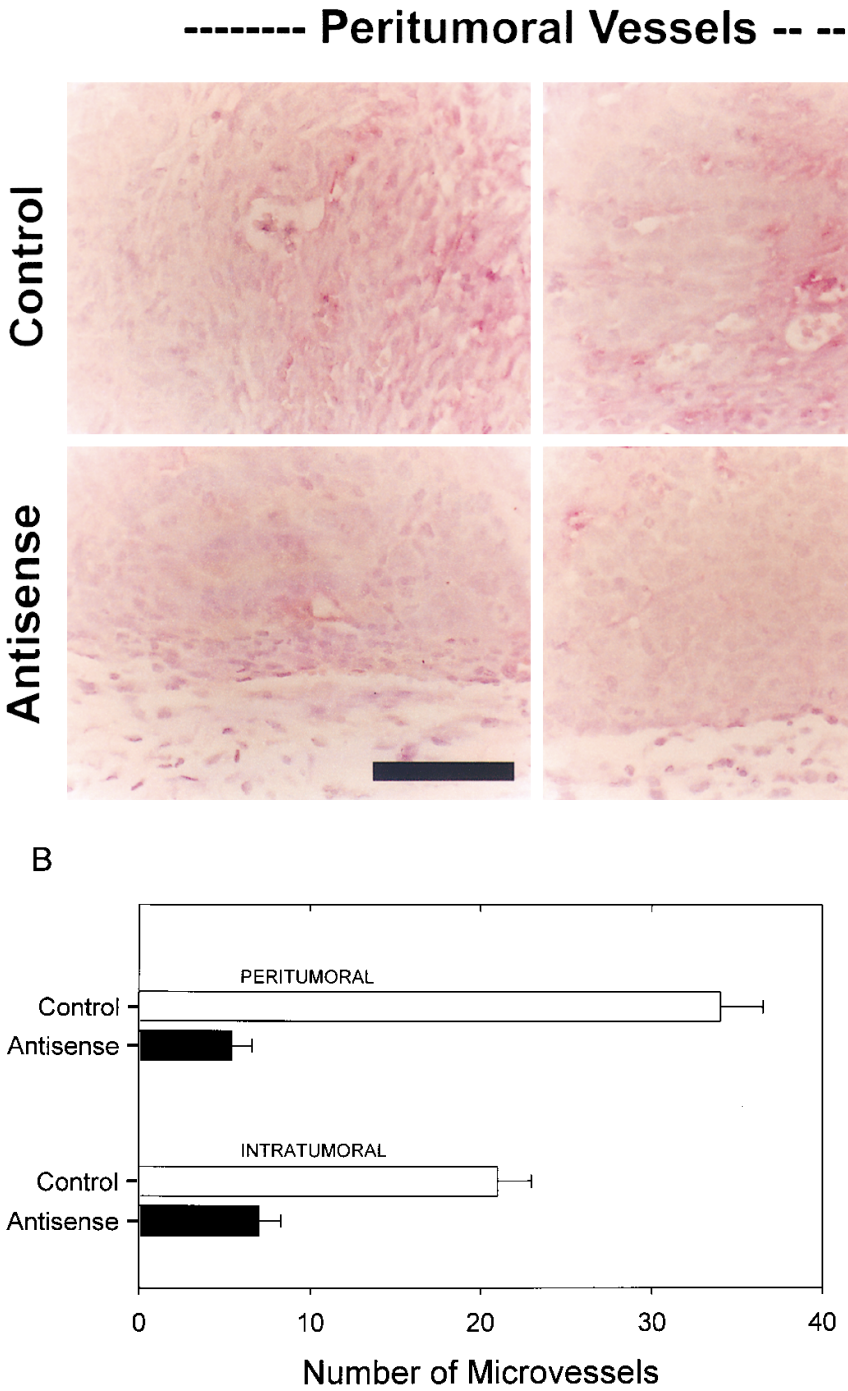

Number of Microvessels
Figure 5. Abrogated perlecan expression causes a reduction in tumor neovascularization. ( $A$ ) Immunohistochemical localization (red staining) of perlecan in the peritumoral and intratumoral regions of the colon carcinoma xenografts. Notice the significant reduction of perlecanlabeled microvessels in the antisense AS2 tumor xenografts. Scale bar, $50 \mu \mathrm{m}$. (B) Microvessel density in control and antisense-expressing AS2 tumor xenografts. The data were generated from counting recognizable microvessels reactive with the antiperlecan antibody in $\times 200$ fields ( $n=35-45 /$ each tumor). The differences are statistically significant $(P<0.0001)$ using the paired Student's $t$ test. served 8 wk after injection. Staining of the tumor tissue with antiperlecan antibodies showed a marked suppression of the tumor microvessel density in the antisense-induced tumors (not shown) similar to the results obtained with the human colon carcinoma cells. Thus, conditional abrogation of perlecan gene expression suppresses tumor growth and angiogenesis in tumor allografts induced by mouse melanoma cells. Because these data were obtained in syngeneic animals with results comparable to those obtained in nude mice, we conclude that inhibition of tumor growth and angiogenesis in the perlecandeficient tumor cells is independent of immune competence.

\section{Discussion}

The angiogenic phenotype is considered decisive for tumor progression (1) and recent evidence indicates that several key molecules involved in this complex biological event are potential candidates for therapeutic intervention. For example, inhibition of tumor growth in vivo can be mediated by: $(a)$ angiostatin, a protein that selectively instructs endothelia to become refractory to angiogenic stimuli (3); (b) blocking vas- cular endothelial growth factor receptor (31); (c) a variety of antiangiogenic inhibitors including AGM-1470 and the antibiotic minocycline (32); and $(d)$ antisense strategies targeting either FGF-2 or its receptor $(26,29)$. Neovascularization is a key event for protracted tumor growth since it provides proper oxygen supply, nutrient perfusion, and removal of toxic by-products. Thus, it is not surprising that other molecules involved in vascular cell biology may also affect tumor angiogenesis.

There is mounting evidence for the involvement of perlecan in tumor progression and vascularization $(5,33)$. The common theme emerging from experimental evidence is that aggressive behavior coincides with augmented synthesis and secretion of this potent and ubiquitous angiogenic stimulant $(12,16)$. Moreover, the source of perlecan is dual since both cancer and stromal cells synthesize it (5). Thus, the growing neoplastic cells as well as the stromal elements would benefit from a relatively high and constant supply of this large macromolecule harboring heparan sulfate chains and cell-adhesive motifs in the protein core. Perlecan would contribute to the scaffold upon which growth factors, i.e., FGF-7 for epithelial cells and FGF-2 for mesenchymal cells, would rest and operate 


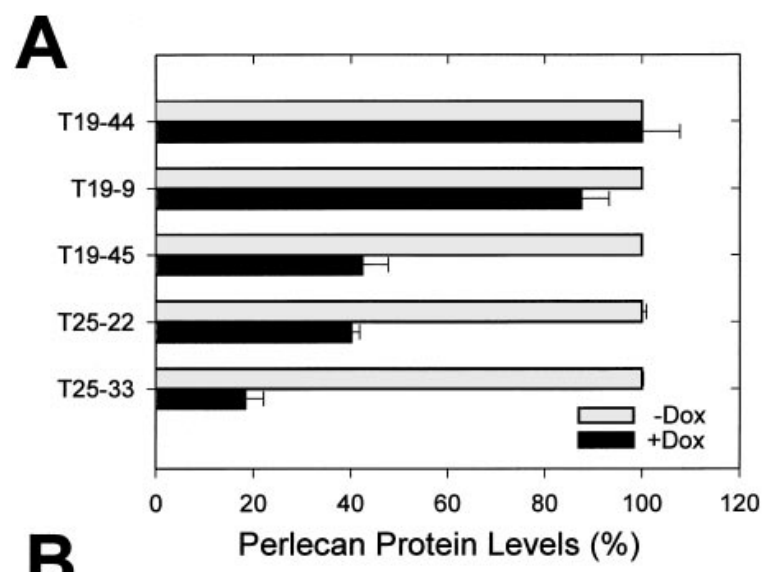

B

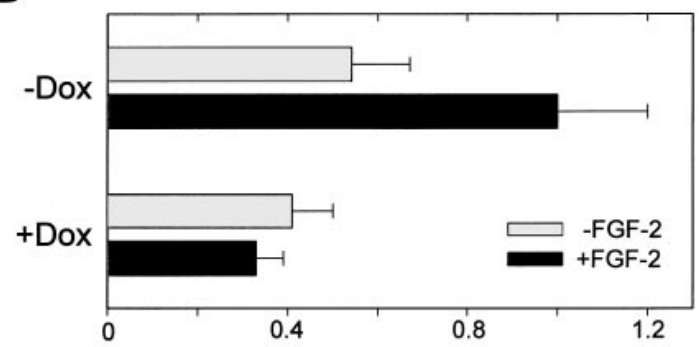

Absorbance Units $(490 \mathrm{~nm})$

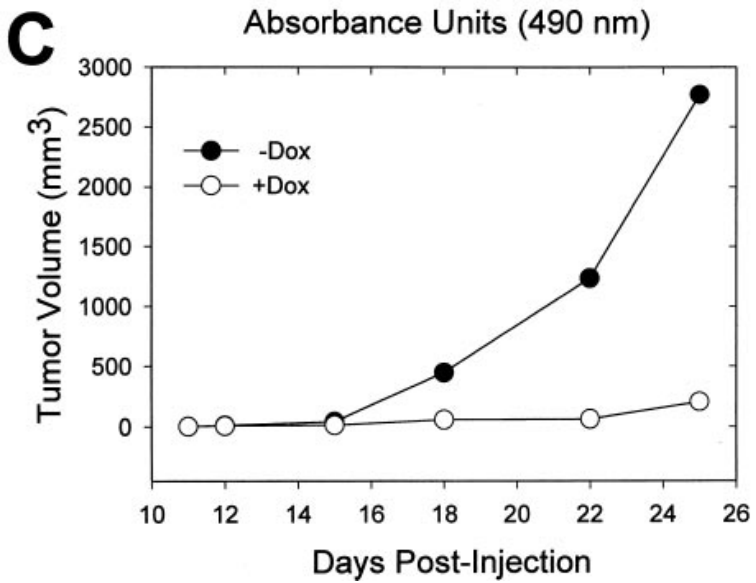

Figure 6. Conditional suppression of mouse perlecan caused by doxycycline-inducible perlecan antisense vectors leads to reduced growth of mouse melanoma cells in syngeneic animals. $(A)$ Quantification of perlecan protein core levels in serum-free media conditioned by various antisense-expressing clones with or without doxycycline using Western immunoblotting and an affinity-purified rabbit anti-mouse perlecan antibody (8) and chemiluminescence. Values are the means of quadruplicate determinations $\pm \mathrm{SD}$. (B) Growth response of T2533 clonal cells in the presence or absence of doxycycline $(2 \mu \mathrm{g} / \mathrm{ml})$ and/or FGF-2 $(10 \mathrm{ng} / \mathrm{ml})$ as indicated. The values are the means of quadruplicate samples \pm SEM. $(C)$ Growth of M2 antisense clone T25-33 in syngeneic animals. Approximately $1.1 \times 10^{6}$ cells were injected into 20 syngeneic $\mathrm{C} 3 \mathrm{H} / \mathrm{HeN}$ mice (males, 5-6 wk old). Half of the animals received in their drinking water $5 \%$ sucrose (filled circles) and the other half $5 \%$ sucrose plus $400 \mu \mathrm{g} / \mathrm{ml}$ doxycycline (open circles). The data represent the means with SD $<15 \%$ of the mean.

their activities. It should be pointed out, however, that perlecan synthesized by vascular endothelial cells has been shown to be a potent inhibitor of smooth muscle cell proliferation (34) as well as FGF-2 binding and mitogenic stimulation of these cells (35). Thus, it is possible that perlecan might exert multiple activities depending upon the tissue and the pathologic process.

In this report we demonstrate for the first time that a reduction of perlecan gene expression causes inactivation of FGF-7 binding and receptor modulation. Reduced affinity for FGF-7 in the antisense-expressing colon carcinoma cells and full restoration of the FGF-7 mitogenic activity by nanomolar concentrations of exogenous perlecan further prove that proper perlecan gene expression is required for FGF-7 binding and receptor activation in carcinomas. We demonstrate that this is a heparin-independent phenomenon, thereby raising the possibility that the perlecan protein core is directly involved in modulating FGF-7 activity. The specific binding of FGF-7 to immobilized perlecan further indicates a potential functional interaction between the growth factor and the perlecan protein core. This interaction is currently under investigation in our laboratory. We also show that inhibition of tumor angiogenesis by blocking perlecan expression prevents neoplastic growth and invasion into the deep muscular layers. The intratumoral and peritumoral microvessel density is significantly reduced in the antisense-expressing tumor xenografts and the overall growth is also abrogated in allografts of highly metastatic melanomas. In the latter, the only difference between the two conditions was the presence of doxycycline in the drinking water. The pharmacokinetics of this drug have been well investigated in mice and no toxic effects or histopathological changes were detected after a 3-mo regimen (30). Our results are in full agreement with a recent report indicating that suppression of perlecan synthesis in melanoma cells, by using antisense targeting as in our case, reduces cell proliferation, in vitro invasion, and metastatic potential in an animal model of lung metastasis (17).

There are several potent angiogenesis inhibitors that are proteolytically processed from larger parent molecules that per se are not angiogenic. For example, a $38-\mathrm{kD}$ internal fragment of plasminogen termed angiostatin (36) and a $20-\mathrm{kD}$ COOH-terminal fragment of collagen type XVIII termed endostatin (37) inhibit endothelial cell proliferation and angiogenesis. A recurrent theme in regulating tumor angiogenesis is the storage of these angiogenic blockers as cryptic fragments of abundant proteins associated with the vascular system (38). Although the general mechanisms by which these unrelated molecules exert their function are not known, recent crystallographic data on endostatin have provided the first clue of potential mechanism of action (39). The structure reveals a compact fold distantly related to the C-type lectin and harbors a large basic patch of 11 arginine residues that can explain its high affinity for heparin. Thus, endostatin may inhibit angiogenesis by binding to and blocking heparan sulfate moieties involved in growth factor signaling.

In conclusion, perlecan gene expression not only confers a growth advantage but is an essential component of the multifactorial and highly complex process that leads to proper tumor capillarization. It is not surprising that agents such as tumor necrosis factor- $\alpha$ or interferon- $\gamma$, which are both antiangiogenic, are also potent downregulators of perlecan gene expression $(21,40)$. Because targeting perlecan acts primarily on the stromal neovessels, a compartment that includes genetically stable endothelial cells less likely to acquire resistance, therapies focused on abrogating perlecan expression may prove to be beneficial and may potentially improve cancer treatment. 


\section{Acknowledgments}

We thank Drs. P. Yurchenco, M. Dziadek, J. Hassell, and I.J. Fidler for their generous gifts of reagents.

This work was supported by National Institutes of Health grants RO1 CA39481 and RO1 CA47282 (to R.V. Iozzo), and RO1 HL56200 and RO1 EY11004 (to M.A. Nugent).

\section{References}

1. Hanahan, D., and J. Folkman. 1996. Patterns and emerging mechanisms of the angiogenic switch during tumorigenesis. Cell. 86:353-364.

2. Holmgren, L., M. O'Reilly, and J. Folkman. 1995. Dormancy of micrometastases: balanced proliferation and apoptosis in the presence of angiogenesis suppression. Nat. Med. 1:149-153.

3. O'Reilly, M.S., L. Holmgren, C. Chen, and J. Folkman. 1996. Angiostatin induces and sustains dormancy of human primary tumors in mice. Nat. Med. 2: 689-692.

4. Folkman, J., and P.A. D'Amore. 1996. Blood vessel formation: what is its molecular basis? Cell. 87:1153-1155.

5. Iozzo, R.V. 1998. Matrix proteoglycans: from molecular design to cellular function. Annu. Rev. Biochem. 67:609-652.

6. Noonan, D.M., A. Fulle, P. Valente, S. Cai, E. Horigan, M. Sasaki, Y. Yamada, and J.R. Hassell. 1991. The complete sequence of perlecan, a basement membrane heparan sulfate proteoglycan, reveals extensive similarity with laminin A chain, low density lipoprotein-receptor, and the neural cell adhesion molecule. J. Biol. Chem. 266:22939-22947.

7. Iozzo, R.V., I.R. Cohen, S. Grässel, and A.D. Murdoch. 1994. The biology of perlecan: the multifaceted heparan sulphate proteoglycan of basement membranes and pericellular matrices. Biochem. J. 302:625-639.

8. Handler, M., P.D. Yurchenco, and R.V. Iozzo. 1997. Developmental expression of perlecan during murine embryogenesis. Dev. Dyn. 210:130-145.

9. Cohen, I.R., A.D. Murdoch, M.F. Naso, D. Marchetti, D. Berd, and R.V. Iozzo. 1994. Abnormal expression of perlecan proteoglycan in metastatic melanomas. Cancer Res. 54:5771-5774.

10. Timar, J., A. Ladanyi, K. Lapis, and M. Moczar. 1992. Differential expression of proteoglycans on the surface of human melanoma cells characterized by altered experimental metastatic potential. Am. J. Pathol. 141:467-474.

11. Vigny, M., M.P. Ollier-Hartmann, M. Lavigne, N. Fayein, J.C. Jeanny, M. Laurent, and Y. Courtois. 1988. Specific binding of basic fibroblast growth factor to basement membrane-like structures and to purified heparan sulfate proteoglycan of the EHS tumor. J. Cell. Physiol. 137:321-328.

12. Aviezer, D., D. Hecht, M. Safran, M. Eisinger, G. David, and A. Yayon. 1994. Perlecan, basal lamina proteoglycan, promotes basic fibroblast growth factor-receptor binding, mitogenesis, and angiogenesis. Cell. 79:1005-1013.

13. Yayon, A., M. Klagsbrun, J.D. Esko, P. Leder, and D.M. Ornitz. 1991. Cell surface, heparin-like molecules are required for binding of basic fibroblast growth factor to its high affinity receptor. Cell. 64:841-848.

14. Ornitz, D.M., A. Yayon, J.G. Flanagan, C.M. Svahn, E. Levi, and P. Leder. 1992. Heparin is required for cell-free binding of basic fibroblast growth factor to a soluble receptor and for mitogenesis in whole cells. Mol. Cell. Biol. 12:240-247.

15. Whitelock, J.M., A.D. Murdoch, R.V. Iozzo, and P.A. Underwood. 1996. The degradation of human endothelial cell-derived perlecan and release of bound basic fibroblast growth factor by stromelysin, collagenase, plasmin and heparanases. J. Biol. Chem. 271:10079-10086.

16. Aviezer, D., R.V. Iozzo, D.M. Noonan, and A. Yayon. 1997. Suppression of autocrine and paracrine functions of basic fibroblast growth factor by stable expression of perlecan antisense cDNA. Mol. Cell. Biol. 17:1938-1946.

17. Adatia, R., A. Albini, S. Carlone, D. Giunciuglio, R. Benelli, L. Santi, and D.M. Noonan. 1998. Suppression of invasive behavior of melanoma cells by stable expression of anti-sense perlecan cDNA. Ann. Oncol. 8:1257-1261.

18. Mathiak, M., C. Yenisey, D.S. Grant, B. Sharma, and R.V. Iozzo. 1997. A role for perlecan in the suppression of growth and invasion in fibrosarcoma cells. Cancer Res. 57:2130-2136.

19. Murdoch, A.D., G.R. Dodge, I. Cohen, R.S. Tuan, and R.V. Iozzo. 1992. Primary structure of the human heparan sulfate proteoglycan from basement membrane (HSPG2/perlecan). A chimeric molecule with multiple domains homologous to the low density lipoprotein receptor, laminin, neural cell adhesion molecules, and epidermal growth factor. J. Biol. Chem. 267:85448557.

20. Santra, M., T. Skorski, B. Calabretta, E.C. Lattime, and R.V. Iozzo. 1995. De novo decorin gene expression suppresses the malignant phenotype in human colon cancer cells. Proc. Natl. Acad. Sci. USA. 92:7016-7020.

21. Sharma, B., and R.V. Iozzo. 1998. Transcriptional silencing of perlecan gene expression by interferon- $\gamma$. J. Biol. Chem. 273:4642-4646.

22. Murdoch, A.D., B. Liu, R. Schwarting, R.S. Tuan, and R.V. Iozzo. 1994. Widespread expression of perlecan proteoglycan in basement membranes and extracellular matrices of human tissues as detected by a novel monoclonal antibody against domain III and by in situ hybridization. J. Histochem. Cytochem. 42:239-249.

23. Fannon, M., and M.A. Nugent. 1996. Basic fibroblast growth factor binds its receptors, is internalized, and stimulates DNA synthesis in Balb/c3T3 cells in the absence of heparan sulfate. J. Biol. Chem. 271:17949-17956.

24. Basilico, C., and D. Moscatello. 1992. The FGF family of growth factors and oncogenes. Adv. Cancer Res. 59:115-165.

25. Aaronson, S.A., D.P. Bottaro, T. Miki, D. Ron, P.W. Finch, T.P. Fleming, J. Ahn, W.G. Taylor, and J.S. Rubin. 1991. Keratinocyte growth factor. A fibroblast growth factor family member with unusual target cell specificity. Ann. NY Acad. Sci. 638:62-77.

26. Wang, Y., and D. Becker. 1997. Antisense targeting of basic fibroblast growth factor and fibroblast growth factor receptor-1 in human melanomas blocks intratumoral angiogenesis and tumor growth. Nat. Med. 3:887-893.

27. Weidner, N., J.P. Semple, W.R. Welch, and J. Folkman. 1991. Tumor angiogenesis and metastasis: correlation in invasive breast carcinoma. N. Engl. J. Med. 324:1-8.

28. Talmadge, J.E., and I.J. Fidler. 1982. Enhanced metastatic potential of tumor cells harvested from spontaneous metastases of heterogenous murine tumors. J. Natl. Cancer Inst. 69:975-980.

29. Becker, D., C.B. Meier, and M. Herlyn. 1989. Proliferation of human malignant melanomas is inhibited by antisense oligodeoxynucleotides targeted against basic fibroblast growth factor. EMBO (Eur. Mol. Biol. Organ.) J. 8: 3685-3691.

30. Kistner, A., M. Gossen, F. Zimmermann, J. Jerecic, C. Ullmer, H. Lübbert, and H. Bujard. 1996. Doxycycline-mediated quantitative and tissue-specific control of gene expression in transgenic mice. Proc. Natl. Acad. Sci. USA. 93:10933-10938.

31. Skobe, M., P. Rockwell, N. Goldstein, S. Vosseler, and N.E. Fusenig. 1997. Halting angiogenesis suppresses carcinoma cell invasion. Nat. Med. 3: 1222-1227.

32. Parangi, S., M. O'Reilly, G. Christofori, L. Holmgren, J. Grosfeld, J. Folkman, and D. Hanahan. 1996. Antiangiogenic therapy of transgenic mice impairs de novo tumor growth. Proc. Natl. Acad. Sci. USA. 93:2002-2007.

33. Iozzo, R.V., and A.D. Murdoch. 1996. Proteoglycans of the extracellular environment: clues from the gene and protein side offer novel perspectives in molecular diversity and function. FASEB (Fed. Am. Soc. Exp. Biol.) J. 10:598614.

34. Benitz, W.E., R.T. Kelley, C.M. Anderson, D.E. Lorant, and M. Bernfield. 1990. Endothelial heparan sulfate proteoglycan. I. Inhibitory effects on smooth muscle cell proliferation. Am. J. Respir. Cell Mol. Biol. 2:13-24.

35. Forsten, K.E., N.A. Courant, and M.A. Nugent. 1997. Endothelial proteoglycans inhibit bFGF binding and mitogenesis. J. Cell. Physiol. 172:209-220.

36. O'Reilly, M.S., L. Holmgren, Y. Shing, C. Chen, R.A. Rosenthal, M. Moses, W.S. Lane, Y. Cao, E.H. Sage, and J. Folkman. 1994. Angiostatin: a novel angiogenesis inhibitor that mediates the suppression of metastases by a Lewis lung carcinoma. Cell. 79:315-328.

37. O'Reilly, M.S., T. Boehm, Y. Shing, N. Fukai, G. Vasios, W.S. Lane, E. Flynn, J.R. Birkhead, B.R. Olsen, and J. Folkman. 1997. Endostatin: an endogenous inhibitor of angiogenesis and tumor growth. Cell. 88:277-285.

38. Sage, E.H. 1997. Pieces of eight-bioactive fragments of extracellular proteins as regulators of angiogenesis. Trends Cell Biol. 7:182-186.

39. Hohenester, E., T. Sasaki, B.R. Olsen, and R. Timpl. 1998. Crystal structure of the angiogenesis inhibitor endostatin in $1.5 \AA$

resolution. EMBO (Eur. Mol. Biol. Organ.) J. 17:1656-1664.

40. Iozzo, R.V., J. Pillarisetti, B. Sharma, A.D. Murdoch, K.G. Danielson, J. Uitto, and A. Mauviel. 1997. Structural and functional characterization of the human perlecan gene promoter. J. Biol. Chem. 272:5219-5228.

41. Hassell, J.R., W.C. Leyshon, S.R. Ledbetter, B. Tyree, S. Suzuki, M. Kato, K. Kimata, and H.K. Kleinman. 1985. Isolation of two forms of basement membrane proteoglycans. J. Biol. Chem. 260:8098-8105. 